\title{
ANALISIS KINERJA DAN EFISIENSI PENGELOLAAN DANA ZAKAT: STUDI BAZNAS YOGYAKARTA PERIODE 2015-2018
}

\author{
Nurfadilah Maulana S \\ Universitas Islam Negeri Sunan Kalijaga Yogyakarta \\ nurfadilahmaulana02@gmail.com \\ Received: 30 Mei 2020; Revised: 5 June 2020; Published: 13 June 2020
}

\begin{abstract}
This research to analyze the performance and efficiency of the institution BAZNAS Yogyakarta as a central institution coordinator gathering Zakat fund that must have a good and efficient performance. This research measures the performance of the Zakat agency through institutional indicators and the impact of the recipient of Zakat from the National Zakat Index (NZI), and measures the efficiency using the method Data Envelopment analysis (DEA). The sample used in this study is the audited financial annual report of 2015-2018. Based on the results of performance analysis, BAZNAS Yogyakarta has an index value of 0.433, which classifies the performance of the Zakat agency as "good enough ", the results of the efficiency analysis of $100 \%$ in the year 2015, 2017 and 2018, subsequently in 2016 only achieve efficiency of 97\% and 3\% that is inefficient. So the results of this research can be a reference for BAZNAS Yogyakarta further improve performance that is still less efficient and maintain the maximum performance to remain the center coordinator of the institution gathering Zakat fund that is entrusted by the Government and people of Yogyakarta.
\end{abstract}

\section{Keyword: Performance; efficiency; zakat}

\begin{abstract}
ABSTRAK
Penelitian ini bertujuan untuk menganalisis kinerja dan efisiensi lembaga BAZNAS Yogyakarta sebagai lembaga pusat koordinator penghimpunan dana zakat yang harus memiliki kinerja yang bagus dan efisien. Penelitian ini mengukur kinerja lembaga Zakat melalui indikator kelembagaan dan dampak penerima zakat dari indeks Zakat Nasional (IZN), dan mengukur efisiensi menggunakan Metode Data Envelopment Analisis (DEA). Sampel yang digunakan dalam penelitian ini adalah laporan tahunan keuangan yang telah diaudit tahun 2015-2018. Berdasarkan hasil analisis kinerja, BAZNAS Yogyakarta memiliki nilai indeks 0,433, yang mengklasifikasikan kinerja lembaga Zakat sebagai "cukup baik", hasil analisis efisiensi $100 \%$ pada tahun 2015, 2017 dan 2018, selanjutnya pada tahun 2016 hanya mencapai efisiensi 97\% dan $3 \%$ yang tidak efisien. Sehingga hasil penelitian ini bisa jadi acuan untuk BAZNAS Yogyakarta lebih meningkatkan kinerja yang masih kurang efisien dan mempertahankan kinerja yang sudah maksimal agar tetap menjadi pusat koordinator lembaga penghimpunan dana zakat yang diberi kepercayaan oleh pemerintah dan masyarakat Yogyakarta.
\end{abstract}

Kata Kunci: Kinerja; zakat; Efisiensi 


\section{PENDAHULUAN}

Zakat merupakan salah satu solusi dari problem yang tengah dihadapi pemerintah yaitu problem tingkat kemiskinan yang sangat tinggi. Zakat memiliki tiga fungsi utama dalam perang pembangunan ekonomi. Pertama, saat digunakan untuk pembatasan anggaran negara, yang digunakan untuk menekan anggaran. Kedua, Zakat berperan sebagai alat keselamatan dan kesejahteraan sosial. Ketiga, Zakat dapat digunakan untuk lebih produktif dalam produksi usaha perekonomian dalam rangka meningkatkan pertumbuhan ekonomi. Sedangkan, menurut (Beik, 2009), Zakat merupakan alat pengentasan kemiskinan yang digunakan untuk menciptakan kesejahteraan sosial ${ }^{1}$, selain itu menurut (Putra, n.d.) Tujuan zakat ada dua yaitu dari segi aspek ibadah dan aspek ekonomi, dari segi aspek ibadah tujuan zakat adalah suatu bentuk penghambaan seorang Muslim kepada sang pencipta langit dan bumi, sedangkan tujuan zakat dari aspek ekonomi adalah sebagai media pemerataan kekayaan agar tidak terjadi kesenjangan sosial².

Menurut Muhammad keberadaan lembaga Zakat saat ini memiliki perang sangat penting untuk kesejahteraan masyarakat dalam membangun ekonomi ${ }^{3}$. Sebelum adanya lembaga Zakat, Zakat didistribusikan oleh perorangan dan berdampak hanya untuk meringankan biaya konsumsi. Kehadiran lembaga Zakat, Dana zakat diharapkan bisa memberikan dampak yang signifikan bagi masyarakat utamanya untuk pembangunan ekonomi, mampu memberikan solusi terhadap masalah kemiskinan dan meningkatkan kesejahteraan masyarakat. Manajemen zakat yang baik oleh lembaga memberikan dampak yang bagus sebagai solusi pembangunan ekonomi, memiliki kekuatan untuk mendorong pertumbuhan ekonomi negara dan masyarakat dengan berupa cara mengentaskan kemiskinan, menghasilkan pendapatan, dan membuka lapangan kerja4. Kehadiran lembaga Zakat diharapkan dapat mengakibatkan perubahan dalam sistem pengumpulan dan pengelolaan zakat.

\footnotetext{
${ }^{1}$ Irfan Syauqi Beik, Analisis Peran Zakat dalam Mengurangi Kemiskinan: Studi Kasus Dompet Dhuafa Republika, Edisi 2009, h. 3.

2Trisno Wardy Putra, Penghimpunan Dana Zakat Infak dan Sedakah di Badan Amil Zakat Nasional, Edisi 2019, h. 249.
}

${ }^{3}$ Muhamad, Zakat Profesi: Wacana Pemikiran dalam Fiqih Kontemporer (Jakarta: Salemba Diniyah, 2002), h. 12.

${ }^{4}$ Muhamad, Zakat Profesi: Wacana Pemikiran dalam Fiqih Kontemporer (Jakarta: Salemba Diniyah, 2002), h. 14. 
Pengukuran kinerja diperlukan untuk memonitor apakah operasi lembaga zakat mencapai tujuan yang telah direncanakan oleh lembaga (Noor \& Khairi, 2014) ${ }^{5}$. Menurut Ahmad indikator yang penting untuk diukur adalah efisiensi, karena efisiensi merupakan hasil maksimum yang dapat diproduksi berdasarkan data yang tersedia 6 . Sedangkan menurut (Rahman, n.d.) Menyatakan bahwa efisiensi pengukuran bukanlah proses yang luas dan kompleks karena menggunakan indeks dan rasio7. Namun, efisiensi berguna untuk memonitor dan meningkatkan kinerja manajemen Zakat. Noor dalam penelitiannya menyatakan bahwa adapun tujuan dari evaluasi kinerja adalah dengan cara mengukur efisiensi lembaga sebagai bentuk transparansi kepada para pemangku kepentingan zakat dan ketaatan kepada Allah SWT. Sehingga tujuan penelitian ini agar mengetahui perkembangan kinerja dan efisiensi lembaga zakat dalam pengelola Dana zakat.

Terdapat dua lembaga Zakat di Indonesia yang bertugas mengurus, mendistribusikan dan memberdayakan Zakat yaitu Lembaga Amil Zakat (BAZ) dan Lembaga Amil Zakat (LAZ) yang membedakan keduanya adalah kepemilikan, BAZ adalah lembaga manajemen Zakat yang didirikan oleh pemerintah sedangkan, LAZ adalah lembaga manajemen yang didirikan oleh Zakat swasta yang sepenuhnya diprakarsai oleh masyarakat. Pada pernyataan (Fuad, n.d.) "BAZNAS Simbol Kemajuan Perzakatan Indonesia”, menyatakan bahwa lembaga yang satu satunya dibentuk oleh pemerintah yang memiliki fungsi dan tugas untuk menghimpun dan mendistribusikan Dana zakat pada tingkat nasional adalah Badan Amil Zakat Nasional (BAZNAS) sehingga dalam hal ini BAZNAS sebagai koordinator dalam mengelola zakat nasional harus sehat dengan memiliki kinerja yang baik dan efisien ${ }^{8}$.

Pada penelitian ini, peneliti fokus membahas Badan Amil Zakat Nasional (BAZNAS) Yogyakarta untuk mengetahui kinerja dan efisiensi lembaga zakat BAZNAS Yogyakarta, beberapa penelitian terdahulu menyatakan bahwa lembaga BAZNAS kurang efektif dan efisien dalam

${ }^{5}$ Noor A.H.M, What the Determine Professionalism? A Study on Zakat Institutions Integration Effort into the Mainstream Economy, Edisi 2014, h. 27.

${ }^{6}$ Ismail HJ Ahmad dan Masturah Ma'in, The Efficiency of Zakat Collection and Distribution: Evidence from Two Stage Analysis, Edisi 2014, h. 35.

${ }^{7}$ Abdul Rahim Abdul Rahman, Pre-Requisites for Effective Integration of Zakah Into mainstream Islamic Financial System in Malaysia, Edisi Januari 2007, h. 98.

${ }^{8}$ Fuad Nasar, BAZNAS Simbol Kemajuan Perzakatan Indonesia. Situs Resmi BAZNAS Pusat, http://www.baznas.go.id, (11 Februari 20015). 
mengelola dana zakat BAZNAS, hasil penelitian Azhar Alam pada lembaga BAZNAS Se-Karesidenan Surakarta menyatakan bahwa terdapat tiga BAZNAS Kabupaten yang kurang efisien dalam mengelola dana zakat ${ }^{9}$. Pada hasil penelitian (Retnowati, 2018) juga menyatakan bahwa lembaga zakat di Jambi, menunjukkan tingkat efisien yang baik dalam mengelola dana zakat yaitu LAZ Jambi mencapai tingkat maksimum 100\% sedangkan BAZNAS Jambi hanya $5,61 \%$ efesien ${ }^{10}$, sehingga dalam hal ini peneliti tertarik melakukan penelitian di BAZNAS Yogyakarta untuk mengetahui apakah BAZNAS Yogyakarta juga mengalami kurang efektif dan efisien dalam mengelola dana zakat dan sebagai bahan evaluasi pengelolaan dana zakat BAZNAS Yogyakarta.

\section{Konsep Zakat}

Zakat merupakan salah satu hal terpenting dalam Islam sebagai instrument sosial ekonomi. Zakat bekerja sebagai sistem yang mampu menerima dengan baik dan didirikan sekitar abad ke-7, ini adalah sistem pajak atau pemasukan keuangan negara pertama yang ada di dunia yang diberlakukan untuk masyarakat yang bercukupan dan memiliki seperangkat peraturan seperti objek zakat dan tariff yang harus dibayarkan (Nishab Zakat) dan penyaluran zakat ${ }^{11}$.

Setelah masyarakat miskin, target Zakat adalah Amil. Amil adalah mereka yang berkontribusi dalam melakukan kegiatan Zakat, mereka yang mengelolah mulai dari penghimpunan Dana Zakat, mendistribusikan ke Mustahik hingga membuat laporan pengeluaran dan pemasukan Dana Zakat. Hafidhudin menyatakan bahwa secara konseptual, Amil Zakat bertugas untuk memetakan Muzaki dan mendata Mustahik, Amil Zakat memberikan bimbingan, pengumpulan dan menerimaan Zakat, dan Mendoakan Musakki ketika mereka menerima Zakat ${ }^{12}$. Selain itu tanggungjawab Amil Zakat ialah memanfaatkan data yang sudah terkumpul untuk memetakan Muzaki dan

${ }^{9}$ Azhar Alam, Analisis efisiensi pengelolaan Dana Zakat Infak Sedekah (ZIS) di Baznas Kabupaten/Kota Se-Karesidenan Surakarta dengan Menggunakan Metode Data Envelopment Analysis DEA, Edisi Oktober 2018, h. 282. 2018, h. 34

${ }^{10}$ Desi Retnowati, The Performance and Efficiency of Zakat Institutions in Jambi, Edisi

${ }^{11}$ Muhammad Aziz dan Sholikah, Metode Istinbat Hukum Zakat Profesi Perspektif Yusuf Al-Qardawi Dan Implikasinya Terhadap Pengembangan Objek Zakat Di Indonesia, Edisi 2015, h. 103.

12Didin Hafidhuddin, Zakat dalam Perekonomian Modern, (Jakarta: Gema insani, 2007), h. 131. 
mendata Mustahik untuk keperluan data agar memudahkan mendistribusikan, dan melakukan pembangunan selanjutnya.

\section{Kinerja dan efisiensi organisasi}

Kinerja organisasi didefinisikan sebagai kemampuan organisasi untuk melaksanakan tugas untuk mencapai tujuannya yang sesuai program visi misi yang telah ditata sebelumnya oleh organisasi dan sesuai kemampuan yang dimilikinya. Konsep kinerja pada suatu lembaga/organisasi terkait tentang pencapain prestasi organisasi atau tujuan organisasi yang terlah ditata sebelumnya telah terpenuhi ${ }^{13}$. (PEBS, 2010) menyatakan bahwa beberapa tujuan untuk mengukur organisasi adalah tujuan pertama memberikan penilaian terhadap kinerja lembaga Zakat. Kedua, memberikan semangat berupa motivasi kepada mereka untuk meningkatkan profesionalisme, transparansi dan akuntanbilitas. Tujuan ketiga, menciptakan suasana yang kondusif untuk pengembangan masyarakat dan tujuan yang terakhir, pengelola zakat diberikan pedoman dalam mendistribusikan dana Zakat ${ }^{14}$.

Efisiensi adalah bagian dari konsep ekonomi. Konsep keseimbangan pasar yang dikenal sebagai teori fundamental ekonomi, konsep efisiensi Pareto menunjukkan kesejahteraan hubungan keseimbangan pasar dan efisiensi alokasi, mengacu pada kondisi dimana alokasi barang dianggap efisien jika tidak ada yang dapat meningkatkan utilitas mereka tanpa mengurangi kegunaan orang lain15.

Penelitian sebelumnya berkaitan erat dengan analisis kinerja dan efisiensi dalam penelitian ini mengenai kinerja lembaga Zakat, atau efisiensi lembaga bertujuan untuk menentukan tingkat efisiensi relatif lembaga Zakat yang menggunakan pendekatan data Envelopment Analysis (DEA)16. Pendekatan yang digunakan oleh (Akbar, 2009) dalam menilai efisiensi menggunakan pendekatan produksi, lembaga Zakat diasumsikan sebagai produsen menghimpun dan mendistribusikan dana zakat. Sehingga demikian,

\footnotetext{
${ }^{13}$ Muhammad Mahsun, Pengukuran Kinerja Sektor Publik, (Yogyakarta: Fakultas Ekonomi UGM, 2006), h. 58.

14PEBS, Indonesia Zakat Development Report: Menggagas Arsitektur Zakat Indonesia, (Jakarta: PEBS UI dan CID, 2010), h. 94.

${ }^{15}$ Adiwarman Karim, Ekonomi Makro Islam, (Jakarta: Raja Grafindo Persada, 2007), h.30.

16Nasher Akbar, Analisis Efisiensi Organisasi Pengelola Zakat Nasional dengan Pendekatan Data Envelopment Analysis, Edisi Desember 2009, h. 764.
} 
penelitian tersebut menunjukkan hasil yang hanya mencerminkan dua aspek efisiensi lembaga zakat.

\section{METODE PENELITIAN}

Studi ini menggunakan data sekunder dan data primer. Data sekunder diperoleh melalui studi literatur dan laporan keuangan audit BAZNAS Yogyakarta tahun 2015-2018, sedangkan data primer diperoleh dari wawancara online melalui kepala cabang BAZNAS Yogyakarta yang mencakup BAZNAS tahun 2015-2018. Penelitian ini merupakan penelitian kuantitatif yaitu menggunakan dua metode penelitian yaitu Indeks indikator kelembagaan Zakat pada Indeks Zakat Nasional (IZN) digunakan untuk mengukur kinerja lembaga Zakat di Provinsi Yogyakarta17, metode kedua yang digunakan adalah data envelopment analisis (DEA) yang digunakan untuk mengukur efisiensi di lembaga zakat ${ }^{18}$. Data dalam penelitian ini diperoleh dengan menggunakan perangkat lunak MaxDEA dan Microsoft Excel 2009.

\section{HASIL PENELITIAN DAN PEMBAHASAN}

\section{Hasil pengukuran kinerja untuk BAZNAS Yogyakarta}

Variabel kinerja lembaga di IZN menggambarkan kinerja manajemen lembaga Zakat dalam menghimpun, mengatur, dan mendistribusikan Dana zakat serta membuat laporan keuangan secara berkala. Analisis kinerja untuk BAZ Yogyakarta diberikan di bawah ini.

Tabel 2. Pengukuran variabel kinerja lembaga BAZNAS Yogyakarta

\begin{tabular}{lllccc}
\hline No & Variabel & Kondisi Lembaga & Nilai & Index & Kinerja \\
\hline 1 & Penghimpunan & $\begin{array}{l}\text { Pertumbuhan dana } \\
\text { zakat } \quad \begin{array}{l}\text { yang } \\
\text { terkumpul adalah 10- }\end{array}\end{array}$ & 0,50 & Cukup \\
& & & & Baik \\
& & & & \\
\hline 2 & Manajemen & $\begin{array}{l}\text { Kinerja pengelolaan } \\
\text { baik, memiliki SOP, }\end{array}$ & & & Baik \\
\hline
\end{tabular}

\footnotetext{
${ }^{17}$ Badan Amil Zakat Nasional, Indeks Zakat Nasional, (Jakarta: Pusat Kajian Strategis BAZNAS, 2016, h. 14.

${ }^{18}$ Saleh Samsubar, Metode Data Envelopment Analysis, (Yogyakarta: FEUGM, 2000), h. 19.
} 


\begin{tabular}{|c|c|c|c|c|c|}
\hline & & $\begin{array}{l}\text { memiliki program } \\
\text { kerja unggulan } \\
\text { tahunan dan strategi } \\
\text { penggalangan dana, } \\
\text { namun tidak ada } \\
\text { sertifikat ISO. }\end{array}$ & & & \\
\hline 3 & Distribusi & $\begin{array}{l}\text { Rasio pendistribusian } \\
\text { adalah } 99,89 \% .\end{array}$ & 3 & 0,50 & $\begin{array}{l}\text { Cukup } \\
\text { Baik }\end{array}$ \\
\hline 4 & Lapaoran & $\begin{array}{lr}\text { Memiliki } & \text { laporan } \\
\text { keuangan } & \text { sesuai } \\
\text { standar dan } & \text { melalui } \\
\text { proses audit. }\end{array}$ & 4 & 0,75 & Baik \\
\hline
\end{tabular}

Sumber: Data Primer Baznas Yogyakarta Tahun 2020

Variabel pertama yaitu penghimpunan, BAZNAS Yogyakarta memiliki pertumbuhan Dana sebesar 10-15\% pertahun. Nilai dari perhitungan indekx penghimpunan yaitu 3 dengan hasil kinerja yang cukup baik karena setiap tahun BAZNAS Yogyakarta selalu mengalami pertumbuhan penghimpunan Dana zakat.

Untuk variabel manajemen, BAZNAS Yogyakarta memperoleh Nilai 4, yang berarti BAZ memiliki program kerja unggulan tahunan, dan memiliki strategi penggalangan dana untuk mencapai target yang sudah ditentukan oleh lembaga, namun tidak memiliki sertifikat ISO. Berdasarkan nilai yang diperoleh, BAZNAS Yogyakarta memperoleh nilai indeks 0,75 menunjukkan kinerja baik, bahwasanya BAZNAS Yogyakarta sudah memenuhi kriteria manajemen yang baik sesuai dengan standar Indeks Zakat Nasional.

Variabel distribusi pada BAZNAS Yogyakarta mendistribusikan 99, 89\% dengan 2 kali termin dalam setahun. Pendistribusian Dana pada BAZNAS Yogyakarta menyesuaikan dengan program BAZNAS pusat yaitu 5 program diantaranya jogja peduli, jogja taqwa, jogja sejahtera, jogja cerdas, dan jogja sehat. BAZNAS Yogyakarta mendistribusikan dana zakat sebanyak 50\% untuk program jogja taqwa dan selebihnya untuk program yang lain, pendistribusian program jogja taqwa lebih tinggi dibanding program-program lainnya. Variabel ini memperoleh nilai 3 dengan nilai index 0, 50 menunjukkan kinerja yang cukup baik. Variabel distrubusi pada BAZNAS Yogyakarta menunjukkan 
cukup baik karena lembaga tersebut mendistribusikan dana zakat pada beberapa program yang sesuai dengan standar BAZNAS pusat.

Variabel terakhir pelaporan BAZNAS Yogyakarta memiliki laporan keuangan yang diterbitkan dan sudah melakukan proses audit sebanyak dua kali yaitu audit internal dan eksternal yang dilakukan oleh pemerintah Kota dan melalui audit syariah, sehingga laporan keuangan BAZNAS sesuai dengan PSAK. Nilai untuk variabel ini yaitu 4, menunjukkan nilai indeks 0, 75, sehingga dapat dikatakan bahwa memiliki kinerja baik, variabel laporan merupakan variabel terakhir dalam mengukur kinerja lembaga menunjukkan kinerja baik karena selain memiliki laporan keuangan yang telah diaudit, BAZNAS Yogyakarta juga mempublikasi laporan keuangan secara berkala.

Tabel 3. Pengukuran variabel dampak zakat BAZNAS Yogyakarta

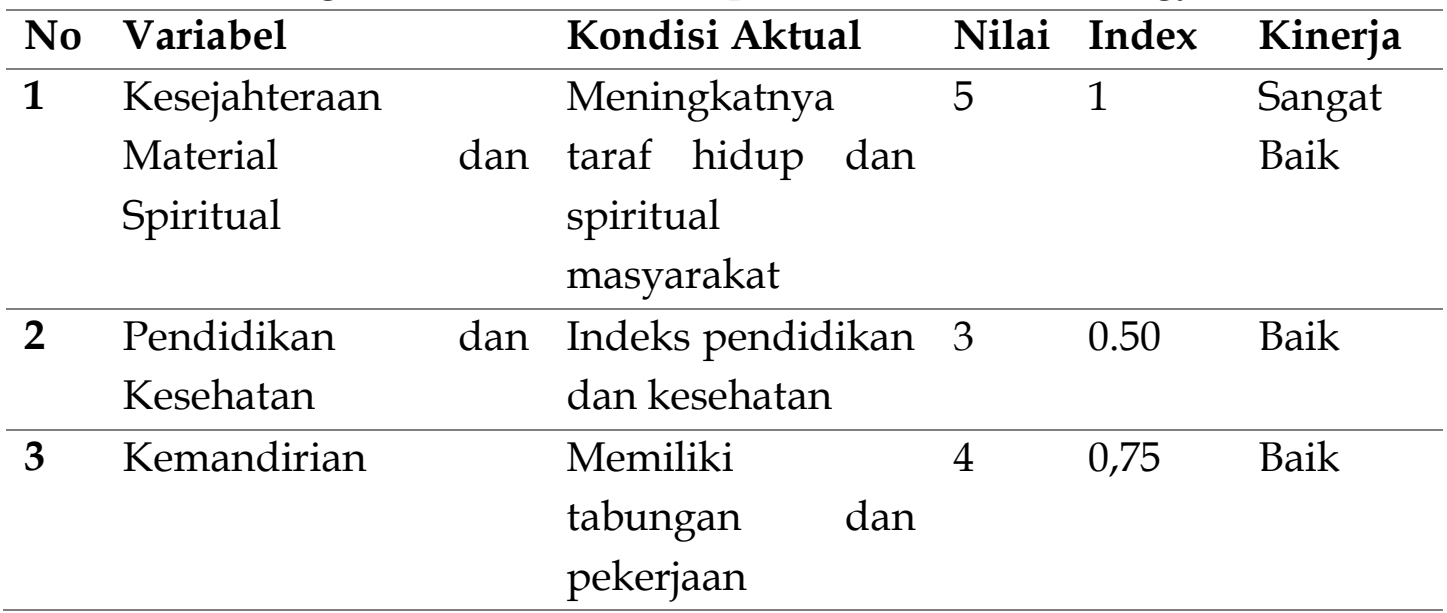

Sumber: Data Primer Baznas Yogyakarta Tahun 2020

Variabel indeks kesejahteraan memiliki nilai 5, yang berarti bahwa lebih dari $80 \%$ dari Mustahik adalah kaya dan material secara spiritual atau dalam Quadrant I (makmur) yaitu 95 Mustahik sehingga nilai indeks kesejahteraan 1, berarti bahwa dampak Zakat yang diberikan BAZNAS Yogyakarta sangat baik. Hasil penelitian dilakukan melalui wawancara di kepala cabang BAZNAS Yogyakarta.

Variabel pendidikan dan kesehatan mendapatkan Skor 3 dan nilai indeks adalah 0, 50. Ini menunjukkan bahwa indeks kesehatan maupun pendidikan dari dampak penerima Zakat bagus. Nilai ini dihitung menyesuaikan harapan hidup untuk kesehatan dan rata-rata jumlah yang sekolah untuk pendidikan.

Variabel terakhir, yaitu nilai kemandirian 4, berarti bahwa Mustahik memiliki pekerjaan atau bisnis yang permanen dan memiliki tabungan 
sehingga mendapatkan nilai indeks 0 , 75 yang berarti dengan index baik. Hal ini memberikan dampak signifikan dari distribusi dana zakat karena dengan menyalurkan dana zakat dengan cara memberikan melalui buku tabungan membuat mustahik memiliki simpanan untuk masa depan yang bisa digunakan saat mustahik membutuhkan dana tersebut.

\section{Hasil pengukuran efisiensi BAZNAS Yogyakarta}

Efisiensi diukur menggunakan metode analisis DEA. Nilai efisiensi diperoleh dengan rentang DEA dari 0 ke 1 . Nilai 1 menunjukkan nilai institusi paling efisien. Semakin dekat nilai efisiensi institusi terhadap 0, semakin tidak efisien institusi ${ }^{19}$.

Metode DEA digunakan untuk mengukur efisiensi institusi. Pengukuran efisiensi yang ditunjukkan pada tabel 4 adalah nilai efisiensi relatif untuk lembaga BAZNAS Yogyakarta yang diperoleh melalui pendekatan intermediasi.

Tabel 4. Variabel Input dan Output BAZNAS Yogyakarta

\begin{tabular}{lclll}
\hline \multirow{2}{*}{ Tahun } & \multirow{2}{c}{ Input } & \multicolumn{2}{c}{ Output } \\
\cline { 2 - 5 } & Total Aset & $\begin{array}{l}\text { Penerimaan } \\
\text { dana zakat }\end{array}$ & $\begin{array}{l}\text { Biaya } \\
\text { operasional }\end{array}$ & $\begin{array}{l}\text { Penyaluran } \\
\text { dana zakat }\end{array}$ \\
\hline $\mathbf{2 0 1 5}$ & $25,718,924$ & $3,892,115,540$ & $40,906,865$ & $3,902,628,938$ \\
\hline $\mathbf{2 0 1 6}$ & $83,733,416$ & $4,395,094,358$ & $21,300,000$ & $4,301,079,766$ \\
\hline $\mathbf{2 0 1 7}$ & $\mathbf{3 8 8 , 5 0 1 , 0 6 5}$ & $4,708,188,632$ & $81,916,844$ & $4,749,690,100$ \\
\hline $\mathbf{2 0 1 8}$ & $422,974,054$ & $4,221,744,777$ & $93,833,821$ & $4,241,804,479$ \\
\hline
\end{tabular}

Sumber: Data Sekunder Baznas Yogyakarta Tahun 2020

Tabel 5. Hasil pengukuran efisiensi metode DEA 2015-2018

\begin{tabular}{cc}
\hline \multicolumn{1}{l}{ Tahun } & Efisiensi BAZNAS Yogyakarta (\%) \\
\hline $\mathbf{2 0 1 5}$ & $100 \%$ \\
\hline $\mathbf{2 0 1 6}$ & $97 \%$ \\
\hline $\mathbf{2 0 1 7}$ & $100 \%$ \\
\hline $\mathbf{2 0 1 8}$ & $100 \%$
\end{tabular}

Sumber: Data Sekunder Yang diolah Tahun 2020

${ }^{19}$ Fakhruddin Masyur, Analisis Perbandingan Efisiensi Bank Umum Syariah dan Bank Umum Konvensional di Indonesia Menggunakan Metode Stochastic Frontier Approach (SFA), Thesis (UIN Sunan Kalijaga Yogyakarta 2012, h. 19). 
Berdasarkan data olahan, BAZNAS Yogyakarta mengalami tingkat efisiensi sebesar 100\% pada tahun 2015, 2017 dan 2018, pada tahun 2016 tingkat efisiensi hanya sebesar $97 \%$. Sehingga ketidakefisienan BAZNAS Yogyakarta pada tahun 2016 yaitu 3\%. Ini menunjukkan bahwa BAZNAS Yogyakarta berhasil mempertahankan tingkat efisiensi sebesar $100 \%$ pada tahun 2015, 2017 dan 2018. Hal ini menunjukkan bahwa Badan Amil Zakat Nasional (BAZNAS) Yogyakarta mampu mengelola input untuk memaksimalkan output.

BAZNAS Yogyakarta mengalami ketidakefisienan tahun 2016 sebesar $3 \%$. Ketidakefisienan ini lazim terjadi karena disebabkan oleh pemakaian aset yang tidak efektif atau ketidakseimbangan antara jumlah dana pada beberapa variabel yang diolah untuk mengukur tingkat efisien.

\section{SIMPULAN}

Secara umum, analisis kinerja lembaga dan dampak penyaluran dana zakat pada lembaga BAZNAS Yogyakarta memiliki kinerja yang baik. BAZNAS Yogyakarta memperoleh nilai indeks kinerja 0,433 dengan demikian menunjukkan kinerja yang cukup baik. Berdasarkan hasil pengukuran analisis efisiensi yang dilakukan BAZNAS Yogyakarta mencapai efisiensi maksimal dengan tingkat efisiensi 100\%, namun hanya di tahun 2016 yang menghasilkan nilai efisiensi $97 \%$ dan $3 \%$ yang tidak efisien pada BAZNAS Yogyakarta. Sehingga hasil penelitian ini bisa jadi acuan untuk BAZNAS Yogyakarta untuk lebih meningkatkan kinerja yang masih kurang efisien dan mempertahankan kinerja yang sudah efisien agar tetap menjadi pusat koordinator lembaga penghimpunan dana zakat yang diberi kepercayaan oleh pemerintah dan masyarakat Yogyakarta. Penelitian selanjutnya bisa menambahkan variabel LAZ untuk menjadi pembanding kinerja dan efisiensi lembaga zakat BAZ dan LAZ dan peneliti selanjutnya disarankan untuk menggunakan metode pendekatan selain DEA untuk mengukur ke akuratan efisiensi lembaga BAZNAS Yogyakarta. 


\section{DAFTAR PUSTAKA}

Akbar, N. (2009). Analisis Efisiensi Organisasi Pengelola Zakat Nasional Dengan Pendekatan Data Envelopment Analysis. 4(2), 25.

Aziz, M., \& Sholikah, S. (2015). Metode Istinbat Hukum Zakat Profesi Perspektif Yusuf Al-Qardawi Dan Implikasinya Terhadap Pengembangan Objek Zakat Di Indonesia. Ulul Albab Jurnal Studi Islam, 16(1), 89. Https://Doi.Org/10.18860/Ua.V16i1.3039

Ahmad, I. \& dan Ma'in M., (2014). “The Efficiency of Zakat Collection and Distribution: Evidence from Two Stage Analysis", Journal of Economic Coorporation and Development", 35(3), pp. 133-170.

Alam, A. (2018), Analisis efisiensi pengelolaan Dana Zakat Infak Sedekah (ZIS) di Baznas Kabupaten/Kota Se-Karesidenan Surakarta dengan Menggunakan Metode Data Envelopment Analysis DEA. (282) pp. 262-290.

Baznas. 2016. Indeks Zakat Nasional puskasbaznas. Jakarta (ID): Badan Amil Zakat Nasional

Beik, O. I. S. (2009). Analisis Peran Zakat Dalam Mengurangi Kemiskinan: Studi Kasus Dompet Dhuafa Republika. 12.

Fuad, N. (N.D.). BAZNAS Simbol Kemajuan Perzakatan Indonesia. Situs Resmi BAZNAS Pusat, Http:/ /Www.Baznas.Go.Id, (11 Februari 20015).

Hafidhuddin, D., (2007). “Zakat dalam Perekonomian Modern”, Jakarta: Gema insani.

Hidayat R. 2014. Efisiensi Perbankan Syariah Teori dan Praktek. Bekasi (ID): Gramata Publising.

Karim, A., A. (2007). Ekonomi Makro Islam, Jakarta (ID): Raja Grafindo Persada.

Lestari, A. (N.D.). Efisiensi Kinerja Keuangan Badan Amil Zakat Daerah (Bazda): Pendekatan Data Envelopment Analysis (Dea). 16, 11.

Mahsun, M. 2006. Pengukuran Kinerja Sektor Publik. Yogyakarta (ID): BPFE Yogyakarta.

Masyur, F. 2012. Analisis Perbandingan Efisiensi Bank Umum Syariah dan Bank Umum Konvensional di Indonesia Menggunakan Metode Stochastic Frontier Approach (SFA). UIN Sunan Kalijaga Yogyakarta. Research Report. 
Muhamad. (2002). Zakat Profesi: Wacana Pemikiran Dalam Fiqih Kontemporer. Salemba Diniyah.

Noor, A. H. M., \& Khairi, N. Z. (2014). What Determine Professionalism? A Study on Zakat Institutions Integration Efforts into the Mainstream Economy. 11.

PEBS. (2010). Indonesia Zakat Development Report: Menggagas Arsitektur Zakat Indonesia. PEBS UI Dan CID.

Putra, T. W. (N.D.). Penghimpunan Dana Zakat Infak Dan Sedekah Di Badan Amil Zakat Nasional. 6, 14.

Rahman, A. R. A. (N.D.). Pre-Requisites for Effective Integration of Zakah into Mainstream Islamic Financial System in Malaysia. Islamic Economic Studies, 14(1), 17.

Retnowati, D. (2018). The Performance and Efficiency of Zakat Institutions in Jambi. 3,12 .

Saleh, S. (2000). Metode Data Envelopment Analysis. Fakultas Ekonomi UGM. 